\title{
Pancreatic Cancer Stem Cells and Relevance to Cancer Treatments
}

\author{
Filip Bednar, ${ }^{1}$ and Diane M. Simeone ${ }^{1,2 *}$ \\ ${ }^{1}$ Department of Surgery, University of Michigan, Ann Arbor, Michigan \\ ${ }^{2}$ Department of Molecular and Integrative Physiology, University of Michigan, Ann Arbor, Michigan
}

\begin{abstract}
Pancreatic cancer continues to be a malignancy with few therapeutic options. The majority of patients that present for an evaluation have locally advanced or metastatic disease that is incurable by surgical approaches. Chemotherapy and radiotherapy resistance of pancreatic adenocarcinomas limits the efficacy of these therapeutic approaches. Recent evidence supports the existence of human pancreatic cancer stem cells, which appear to drive tumor initiation and progression and are particularly resistant to cell death induced by radiation or chemotherapy. Understanding the mechanisms of pancreatic cancer stem cell self-renewal and resistance to standard therapies may lead to new, more effective therapies to treat this dismal disease. J. Cell. Biochem. 107: 40-45, 2009. (c) 2009 Wiley-Liss, Inc.
\end{abstract}

KEY WORDS: CANCER STEM CELLS; PANCREATIC ADENOCARCINOMA; TUMORIGENESIS; STEM CELL SIGNALING; CANCER THERAPY RESISTANCE

$\mathrm{P}$ ancreatic cancer is one of the most lethal known malignancies. Based on the most recent compiled statistical data, the death rate is almost equivalent to its incidence rate. It is estimated that in $2008,37,680$ new cases of pancreatic cancer will be diagnosed in the United States, with 34,290 patients dying from their disease and associated complications [SEER database, National Cancer Institute, 2008]. Despite ongoing extensive research, the incidence and death rates due to pancreatic cancer have not significantly changed over the past 30 years. The majority of pancreatic cancers are pathologically defined as ductal adenocarcinomas and are typically found late in the neoplastic progression, with $50 \%$ of patients presenting with locally advanced unresectable disease and 35\% with metastatic disease. Even in the 15\% of patients who undergo "curative" surgical resection, $75 \%$ of these patients will ultimately succumb to recurrent and metastatic disease. It is clear that new insights into the biology of pancreatic cancer are desperately needed to make inroads into more effective treatment of these patients.

\section{STEM CELL THEORY OF CANCER}

It is well known that majority of tumors, including pancreatic adenocarcinomas, display significant heterogeneity in their respective cell populations. Original models of carcinogenesis explained this diversity by assuming that the associated genetic mutations in tumors occurred in multiple cells and led to increased proliferative potential in the majority of the tumor cells. Accumulating evidence over the past 15 years suggests a different explanation. A "stem cell" theory of cancer [Reya et al., 2001] implies that a small subpopulation of tumor cells is responsible for tumor initiation, growth, and even metastasis. This model is based on normal tissue hierarchical architecture, where a small number of stem or tissue-specific progenitor cancer cells give rise to the terminally differentiated progeny, reproducing the parent tumor, while maintaining a process of self-renewal (Fig. 1).

Initial experiments supporting the cancer stem cell model were performed in the context of hematopoietic malignancies. Work done with acute myeloid leukemia (AML) by Dick and colleagues [Lapidot et al., 1994; Bonnet and Dick, 1997] led to the isolation of a CD34+/ CD38- subpopulation of AML blasts with the functional phenotype of cancer stem cells. These cells were able to successfully engraft into SCID and NOD/SCID mouse bone marrow at very low infusion numbers and recapitulate the phenotypic diversity of the original patient neoplasms during the process of serial passaging through multiple mouse recipients. An interesting observation was the high expression of CD34 on this cell subpopulation, which is also one of the key markers associated with the normal human hematopoietic stem cells. This study gave rise to the notion that at least some malignancies may arise as a result of genetic alterations in tissue stem or progenitor cells.

*Correspondence to: Diane Simeone, MD, Professor, Departments of Surgery and Molecular and Integrative Physiology, University of Michigan Medical Center, TC 2210B, Box 5343, 1500 E. Medical Center Dr., Ann Arbor, MI 48109. E-mail: simeone@umich.edu

Received 12 January 2009; Accepted 14 January 2009 • DOI 10.1002/jcb.22093 • 2009 Wiley-Liss, Inc.

Published online 19 March 2009 in Wiley InterScience (www.interscience.wiley.com). 


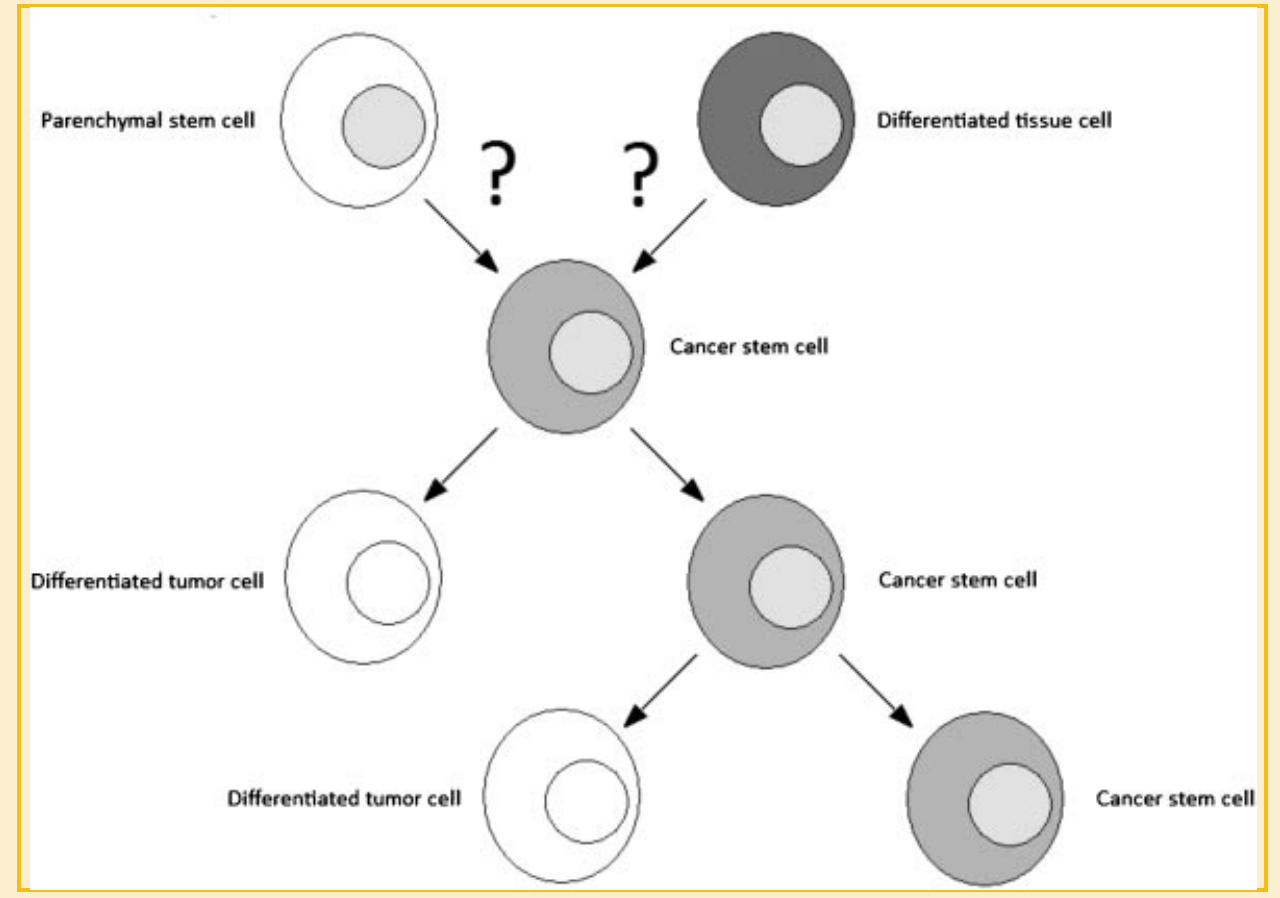

Fig. 1. Cancer stem cell model. It is unclear if cancer stem cells arise due to mutations in tissue parenchymal stem or progenitor cells or differentiated tissue cells. Cancer stem cells then create stem cell progeny by self-renewal and the remaining tumor bulk by tumor-specific cell differentiation.

The applicability of the cancer stem cell concept to a wider range of malignancies was not appreciated until the seminal paper by AlHajj et al. [2003], which was the first demonstration of a cancer stem cell subpopulation in solid tumors. Utilizing xenografts of resected primary human breast cancers or metastatic tumors in NOD/SCID mice, the investigators were able to isolate a CD44+/CD24-/Linsubpopulation of cancer cells which initiated new tumor growth in the mice upon injection of as few as 100 cells. The purified subpopulation was again able to fully recapitulate the phenotypic diversity of the parental tumor even during reisolation and reinjection with serial passages through new recipient mice. Subsequent studies have revealed functional cancer stem cell subpopulations in human brain tumors [Singh et al., 2003], melanomas [Fang et al., 2005], colon cancer [Dalerba et al., 2007; 0'Brien et al., 2007; Ricci-Vitiani et al., 2007], ovarian cancer [Bapat et al., 2005], and head and neck cancers [Prince et al., 2007] (Table I). It is important to emphasize that identification of these

TABLE I. Presence of Cancer Stem Cells in Primary Solid Human Neoplasms

\begin{tabular}{lcl}
\hline Tissue type & Selection markers & \multicolumn{1}{c}{ Refs. } \\
\hline Breast & CD44, CD24, ESA & Al-Hajj et al. [2003] \\
Brain & CD133 & Bao et al. [2006] \\
& CD133 & Singh et al. [2003] \\
Colon & CD44, ESA, CD166 & Dalerba et al. [2007] \\
& CD133 & Ricci-Vitiani et al. [2007] \\
Head and neck & CD133 & O'Brien et al. [2007] \\
Melanoma & CD44 & Prince et al. [2007] \\
Ovary & CD20 & Fang et al. [2005] \\
Pancreas & CD133 & Bapat et al. [2005] \\
& CD44, CD24, ESA & Hermann et al. [2007] \\
\hline
\end{tabular}

cancer stem cell populations was not based solely on expression of specific cell surface markers, but required functional studies to verify that the putative cancer stem cell population possessed the property of self-renewal and the ability to produce differentiated progeny observed in the primary tumor. One of the most basic outstanding questions that exists in the cancer stem cell field is to understand the molecular mechanisms that underlie these characteristics.

\section{ISOLATION AND CHARACTERIZATION OF PANCREATIC CANCER STEM CELLS}

Given the involvement of cancer stem cells in multiple malignancies, we considered the possibility that a similar subpopulation may play a crucial role in the pathogenesis of pancreatic cancer. We adapted a mouse xenograft model to answer this question using primary human resected pancreatic adenocarcinomas. Prior work by Al-Hajj et al. [2003] demonstrated that breast cancer stem cells were highly enriched in the cell subpopulation characterized by CD44, CD24, and epithelial-specific antigen (ESA) expression. We utilized these three markers to sort and prospectively analyze the tumorigenicity of pancreatic cancer cell subpopulations using NOD/ SCID mice as hosts for the cancer xenografts. The cells were sorted using fluorescence-activated cell sorting (FACS) either by single markers or by combinations of CD44, CD24, and ESA. The CD44+/ CD24+/ESA + subpopulation harbored the most tumorigenic cells, with only 100 cells required for tumorigenesis in 6/12 injected mice and comprised only $0.2-0.8 \%$ of the total tumor cell population [Li et al., 2007]. In contrast, the CD44-/CD24-/ESA - subpopulation of 
cells did not successfully engraft despite the injection of up to 10,000 cells. Similar results were obtained on serial passaging and resorting by FACS and subsequent reimplantation. Phenotypic and histologic comparison of the resulting tumors with the primary neoplasms revealed maintenance of the tumor architecture between the serial passages. Therefore, the CD44+/CD24+/ESA+ subpopulation was capable of recapitulating the in vivo tumor growth of the primary tumors. Flow cytometry characterization of the daughter tumors also revealed that the constituent subpopulation frequencies were similar to those originally identified during the process of cell sorting of the primary resected neoplasms. Based on these results, we concluded that the CD44+/CD24+/ESA + subpopulation contains putative pancreatic cancer stem cells, which fulfill the two functional criteria of self-renewal and differentiation into the full spectrum of tumor cell progeny.

A separate characterization of pancreatic cancer stem cells and their involvement in tumor metastasis has been presented by Hermann et al. [2007]. Drawing on prior experiments with brain tumor and hematopoietic stem cells, these authors utilized CD133 as the selection marker for the stem cell subpopulation. Serial passaging experiments of the $\mathrm{CD} 133+$ subpopulation revealed that these cells were able to reconstitute pancreatic tumor growth with full tumor differentiation similar to what we found with our CD44+/ CD24+/ESA+ subpopulation. Further analysis also revealed that a CD133+ stem cell-like subpopulation could be isolated from pancreatic cancer cell lines [Hermann et al., 2007]. Further analysis of multiple cell lines as well as primary pancreatic tumors revealed a subpopulation of CD133+/CXCR4+ cells, which were highly migratory to the CXCR4 ligand chemokine SDF-1 $\alpha$. The migration of the cells could be inhibited in vitro by anti-CXCR4 antibodies. In vivo experiments with cell line-purified CXCR4+ cells demonstrated the requirement for this receptor in generation of pancreatic tumor metastases to the mouse liver [Hermann et al., 2007]. Overall, these results suggest that CXCR4, which has been implicated in metastases of other malignancies and the trafficking of hematopoietic cells, is involved in pancreatic tumor metastasis as well. Phenotypic analysis of the CD44+/CD24+/ESA + subpopulation in primary tumors as well as the employed pancreatic cancer cell lines revealed varying overlap with the $\mathrm{CD} 133+$ population [Hermann et al., 2007]. Whether CD133+ could be added to CD44, CD24, and ESA to further restrict the phenotypic definition of pancreatic cancer stem cells and isolate an even more tumorigenic subset compared to the $\mathrm{CD} 133+$ or $\mathrm{CD} 44+/ \mathrm{CD} 24+/ \mathrm{ESA}+$ subsets remains to be determined.

\section{RESISTANCE OF STEM CELLS TO THERAPY}

The observation that tumors are heterogeneous in terms of their cell populations and contain putative cancer stem cells may in part explain the failure of current treatment approaches using chemotherapy and radiation. These approaches assume that all of the tumor cells will respond to the treatment in a similar manner, ultimately leading to cell death and tumor eradication. Evidence arising from studies of cancer stem cells from several different tumor types points to a contrary conclusion. Observations made with
CD34+/CD38- leukemia-initiating cells demonstrated that these cells had lower uptake of daunorubicin compared to the CD34+/ CD38+ cells [Costello et al., 2000]. This was accompanied by increased induction of multi-drug resistance genes and decreased susceptibility to apoptosis. Radiation and chemotherapy resistance was also observed in the CD44+/CD24- subpopulation of breast cancer-initiating cells. Experiments performed with breast cancer cell lines revealed that increasing doses of radiation led to less apoptosis and more mammosphere-forming activity in the CD44+l CD24- cells compared to the other tumor/cell line subpopulations [Phillips et al., 2006]. Further studies involving chemotherapy were performed utilizing primary breast tumors. In patients with HER2/neu - primary tumors, either docetaxel or doxorubicin/ cyclophosphamide treatments were used. Analysis at 3 and 12 weeks after the start of either chemotherapy regimen found an enrichment of CD44+/CD24- cells in the primary tumors. This correlated with increased mammosphere-forming activity of isolated primary tumor samples [Li et al., 2008]. Interestingly, patients with HER2/neu+ primary tumors who underwent treatment with a molecularly targeted chemotherapy with lapatinib (EGFR/HER2 tyrosine kinase inhibitor) followed by docetaxel and trastuzumab did not exhibit such an increase [Li et al., 2008]. These findings suggest that properly targeted molecular therapy could lead to therapeutic effectiveness against cancer stem cells, which otherwise appear to be enriched or preserved following standard systemic chemotherapy or radiotherapy. Parallel studies in mice revealed that radiation exposure of mouse mammary epithelial cells leads to the enrichment of progenitor cells, which was mediated by the Wnt/ $\beta$-catenin pathway [Woodward et al., 2007]. Animal models could therefore present a tractable system in which to further study the mechanisms of chemotherapy and radiotherapy resistance in cancer stem cells.

Resistance to chemotherapy and radiotherapy has been observed in cancer stem cells in other solid tumors. In primary human gliomas, CD133+ cancer stem cells mediate tumor radiotherapy resistance [Bao et al., 2006]. Exposure of glioma xenografts to radiation led to enrichment of $\mathrm{CD} 133+$ cancer stem cells. The CD133+ cells demonstrated radioresistance in vitro as well, which appeared to be mediated by the Chk1/Chk2 pathway. The glioma CD133+ cells preferentially activated the DNA-damage checkpoint machinery and were able to more efficiently repair radiationinduced DNA damage than their CD133- counterparts [Bao et al., 2006]. Colon CD133+ cancer stem cells were previously shown to be resistant to the standard chemotherapy drugs cyclophosphamide and irinotecan [Dylla et al., 2008]. When colon tumors were treated with oxaliplatin or 5-fluorouracil, the resistance to these chemotherapy agents was found to be mediated by interleukin-4 inhibition of cell apoptosis [Todaro et al., 2007]. These data suggest that diverse mechanisms may underlie the observed resistance of cancer stem cells from different tumor types to chemotherapy and radiation.

Experiments aimed at elucidating the therapeutic relevance of cancer stem cells in pancreatic cancer have also been reported. Treatments of the pancreatic cancer cell line L3.6pl with gemcitabine lead to the enrichment of the CD133+ cancer stem cell-like subpopulation. This finding correlated with decreased apoptosis of the $\mathrm{CD} 133+$ subpopulation upon gemcitabine treatment in primary 
human pancreatic adenocarcinomas [Hermann et al., 2007]. L3.6pl and AsPC-1 cell line treatment with gemcitabine also led to the relative enrichment of the CD44+/CD24+/ESA+ cancer stem cell subpopulation. This was accompanied by the presence of the epithelial-mesenchymal transition (EMT) and a more invasive phenotype for the remaining surviving cells [Shah et al., 2007]. Therefore the paradigm of systemic therapy resistance, which is a known characteristic of pancreatic adenocarcinomas, may be at least partially explained by the presence of pancreatic cancer stem cells and their specific insensitivity to the chemotherapy- and radiation-induced cytotoxicity.

\section{MOLECULAR PATHWAYS UNDERLYING CANCER STEM CELL FUNCTION}

One of the key questions facing the cancer stem cell field is to understand the molecular mechanisms that set cancer stem cells apart from the rest of the tumor progeny and how cancer stem cells regulate self-renewal. Insights gained in the study of normal stem cell function may be applicable to the understanding of cancer stem cells. Several canonical signaling pathways have now been described and found to be involved in stem cell self-renewal and have also been linked to oncogenesis, including the hedgehog, Bmi-1, Wnt signaling pathways (Table II).

The hedgehog family of proteins serve as secreted proteins that work in a paracrine/autocrine manner by binding to the patched (Ptc) receptor, which subsequently relieves the repression of the smoothened (Smo) receptor [Kalderon, 2000]. This signal leads to the activation of the Gli-family transcription factors and initiation of a transcriptional program, which is involved in cell self-renewal, differentiation, and body plan patterning. Upregulation of Hedgehog signaling has been implicated in cerebellar development and the generation of medulloblastomas [Leung et al., 2004]. Hedgehog pathway signaling has also been shown to play a key role in the pathogenesis of pancreatic and other gastrointestinal cancers [Berman et al., 2003; Thayer et al., 2003]. Cyclopamine, a Hedgehog pathway inhibitor, strongly inhibits pancreatic cancer propagation in mice and significantly reduces the proportion of proliferating cells in pancreatic tumor cell lines. In addition, no specific Hedgehog expression is found in the normal differentiated adult pancreas and is only upregulated together with patched in neoplastic pancreatic tissue [Thayer et al., 2003]. We hypothesized that the increased Hedgehog signaling would correlate with the pancreatic cancer stem cell phenotype. In support of this argument, when we examined the expression of Sonic Hedgehog in subsets of pancreatic cancer cells, we observed that the CD44+/CD24+/ESA+ pancreatic cancer stem cell subset had an approximately 46-fold increase in Shh mRNA compared to normal pancreatic cells and a 4-fold increase compared to the bulk pancreatic cancer cells and the isolated CD44-/CD24-/ ESA - cell subpopulation [Li et al., 2007]. This suggests that the cancer stem cell population in pancreatic cancer actively participates in overactive $\mathrm{Hh}$ signaling underlying pancreatic cancer initiation and growth.

Bmi-1 is a member of the Polycomb gene family of epigenetic regulators. The general mechanism of transcriptional regulation by the Polycomb proteins involves post-translational modification of histones, which in turn controls the physical accessibility of the DNA to the transcription machinery [Schuettengruber et al., 2007]. Bmi-1 maintains progression through the cell cycle by transcriptional repression of the ink $4 a$ locus. When Bmi-1 is deleted, p16 and p19 cyclin-dependent kinase inhibitor expression is amplified, leading to premature cellular senescence [Jacobs et al., 1999]. Bmi-1 has been found to be functionally important in stem cell biology by promoting stem cell self-renewal. For example, it is a critical factor in the maintenance of adult hematopoietic stem cells [Lessard and Sauvageau, 2003; Park et al., 2003]. Bmi-1 knockout mice demonstrated significantly decreased numbers of hematopoietic stem cells and increased expression of p16 and p19, leading to proliferative arrest in the cells. Studies performed with leukemic stem cells also demonstrated a requirement for Bmi-1 in maintaining the leukemic stem cell proliferative status and selfrenewal [Lessard and Sauvageau, 2003]. Neural stem cell selfrenewal is similarly dependent on Bmi-1 [Molofsky et al., 2003] and Bmi-1, in conjunction with Sonic Hedgehog, participates in cerebellar development and medulloblastoma formation [Leung et al., 2004]. The role of Bmi-1 in pancreatic cancer stem cell function and pancreatic tumorigenesis is currently being tested.

The Wnt/ $\beta$-catenin pathway was originally defined in Drosophila melanogaster as a pathway responsible for body plan patterning. It has also been shown to be involved in mammalian tissue differentiation and organization. The Wnt signaling cascade is initiated by binding of Wnt to the receptor complex of Frizzled and LRP. Activation of the receptor leads to the dissociation of the Dishevelled (Dsh)/Axin/APC/GSK3- $\beta / \beta$-catenin complex, which normally promotes $\beta$-catenin ubiquitination and degradation [Reya and Clevers, 2005]. Dissociation of the complex liberates $\beta$-catenin which serves to activate the LEF/TCF family of transcription factors. The importance of this pathway in tumorigenesis is well-studied in many cancer types. Mutations of adenomatous polyposis coli (APC) protein leading to decreased degradation of $\beta$-catenin and subsequent transcriptional activation are a key mechanism underlying colon carcinogenesis [Bienz and Clevers, 2000]. $\beta$-catenin signaling has been shown to underlie the continued existence and

TABLE II. Signaling Pathways Involved in Stem Cell Function

\begin{tabular}{|c|c|}
\hline Signaling pathway & Function \\
\hline Hedgehog & Maintenance of stem cell pools by self-renewal, differentiation of progenitors/tissue patterning \\
\hline Bmi-1 (Polycomb proteins) & Chromatin remodeling, cell cycle progression by regulation of cyclins/cyclin-dependent kinases \\
\hline Wnt/ $\beta$-catenin & Self-renewal of stem cell pools and tissue patterning/differentiation \\
\hline Others-Pten, telomerase, Notch & Self-renewal and differentiation of stem cells and progenitors. Telomerase serves as a marker with high activity in stem cell pools \\
\hline
\end{tabular}


self-renewal of colonic crypt progenitor cells, which serve to populate the colonic epithelium [van de Wetering et al., 2002]. This was mediated by the TCF-4 transcription factor and upregulation of c-Myc, which in turn suppresses the p21CIP1/WAF1 cell cycle regulator. Therefore Wnt signaling directly controls the continuous progression of the colonic crypt progenitor cells through the cell cycle and the process of self-renewal. In colon cancers, $\beta$-catenin signaling is aberrantly activated away from the crypt niche, which results in dysregulated self-renewal and maintenance of a colon progenitor/stem cell phenotype, leading to dysplastic polyp growth. Whether Wnt signaling is similarly involved in pancreatic cancer stem cell function is unknown at this time and remains a question to be answered experimentally.

\section{FUTURE DIRECTIONS AND QUESTIONS}

The existence of pancreatic cancer stem cells alters how we view pancreatic tumor initiation and growth. Many new questions have arisen as a consequence. The inherent cellular heterogeneity of tumors leads to questions regarding the relationship between the different tumor cellular populations and how this affects overall tumor progression and metastatic potential. There is some evidence that pancreatic cancer stem cells might directly participate in the metastatic process [Hermann et al., 2007]. We do not know whether all cancer stem cells are capable of metastasis or if a specific subset of cells in the outer periphery of the primary tumor is uniquely positioned to do so. Key questions regarding the molecular mechanisms of self-renewal, proliferation, and differentiation of pancreatic cancer stem cells remain to be answered. We have previously demonstrated upregulation of Hedgehog expression in the pancreatic stem cell subpopulation [Li et al., 2007]. Further studies are currently underway to better delineate how Hedgehog, Wnt, and Bmi1 signaling affect pancreatic cancer stem cell function. It will be interesting to see which cell subsets within the tumor secrete Wnt and Hedgehog ligands and which subsets of cells respond to these ligands to promote tumorigenesis. It is likely that the tumor microenvironment impacts cancer stem cell function and participates in tumor progression. The effects of stem cell niches on their function have been studied in normal stem cell systems and found to play a critical role [Morrison and Spradling, 2008]. Of interest, a recent report implicated tumor-associated stromal fibroblasts in pancreatic cancer growth [Hwang et al., 2008]. The existence of cancer stem cells also has direct therapeutic implications. Current systemic therapies have been found ineffective, and this may be due, at least in part, to increased resistance of the cancer stem cells. Selective pressure provided by the chemotherapy or radiation allows for the survival of the resistant cells and subsequent reconstitution of the primary tumor with cells that will not be responsive to further treatment cycles. It will be important to understand how cancer stem cells are different from the rest of the tumor cell population in order to develop effective targeted therapeutics to prevent tumor reconstitution. The discovery of cancer stem cells provides a new exciting paradigm for understanding cancer and has the potential to lead to significant advancements in its treatment.

\section{REFERENCES}

Al-Hajj M, Wicha MS, Benito-Hernandez A, Morrison SJ, Clarke MF. 2003. Prospective identification of tumorigenic breast cancer cells. Proc Natl Acad Sci USA 100:3983-3988.

Bao S, Wu Q, McLendon RE, Hao Y, Shi Q, Hjelmeland AB, Dewhirst MW, Bigner DD, Rich JN. 2006. Glioma stem cells promote radioresistance by preferential activation of the DNA damage response. Nature 444:756-760.

Bapat SA, Mali AM, Koppikar CB, Kurrey NK. 2005. Stem and progenitor-like cells contribute to the aggressive behavior of human epithelial ovarian cancer. Cancer Res 65:3025-3029.

Berman DM, Karhadkar SS, Maitra A, Montes De Oca R, Gerstenblith MR, Briggs K, Parker AR, Shimada Y, Eshleman JR, Watkins DN, Beachy PA. 2003. Widespread requirement for Hedgehog ligand stimulation in growth of digestive tract tumours. Nature 425:846-851.

Bienz M, Clevers H. 2000. Linking colorectal cancer to Wnt signaling. Cell 103:311-320.

Bonnet D, Dick JE. 1997. Human acute myeloid leukemia is organized as a hierarchy that originates from a primitive hematopoietic cell. Nat Med 3:730-737.

Costello RT, Mallet F, Gaugler B, Sainty D, Arnoulet C, Gastaut JA, Olive D. 2000. Human acute myeloid leukemia CD34+/CD38- progenitor cells have decreased sensitivity to chemotherapy and Fas-induced apoptosis, reduced immunogenicity, and impaired dendritic cell transformation capacities. Cancer Res 60:4403-4411.

Dalerba P, Dylla SJ, Park IK, Liu R, Wang X, Cho RW, Hoey T, Gurney A, Huang EH, Simeone DM, Shelton AA, Parmiani G, Castelli C, Clarke MF. 2007. Phenotypic characterization of human colorectal cancer stem cells. Proc Natl Acad Sci USA 104:10158-10163.

Dylla SJ, Beviglia L, Park IK, Chartier C, Raval J, Ngan L, Pickell K, Aguilar J, Lazetic S, Smith-Berdan S, Clarke MF, Hoey T, Lewicki J, Gurney AL. 2008. Colorectal cancer stem cells are enriched in xenogeneic tumors following chemotherapy. PLoS ONE 3:e2428.

Fang D, Nguyen TK, Leishear K, Finko R, Kulp AN, Hotz S, Van Belle PA, Xu X, Elder DE, Herlyn M. 2005. A tumorigenic subpopulation with stem cell properties in melanomas. Cancer Res 65:9328-9337.

Hermann PC, Huber SL, Herrler T, Aicher A, Ellwart JW, Guba M, Bruns CJ, Heeschen C. 2007. Distinct populations of cancer stem cells determine tumor growth and metastatic activity in human pancreatic cancer. Cell Stem Cell $1: 313-323$.

Hwang RF, Moore T, Arumugam T, Ramachandran V, Amos KD, Rivera A, Ji B, Evans DB, Logsdon CD. 2008. Cancer-associated stromal fibroblasts promote pancreatic tumor progression. Cancer Res 68:918-926.

Jacobs JJ, Kieboom K, Marino S, DePinho RA, van Lohuizen M. 1999. The oncogene and Polycomb-group gene bmi-1 regulates cell proliferation and senescence through the ink4a locus. Nature 397:164-168.

Kalderon D. 2000. Transducing the hedgehog signal. Cell 103:371-374.

Lapidot T, Sirard C, Vormoor J, Murdoch B, Hoang T, Caceres-Cortes J, Minden M, Paterson B, Caligiuri MA, Dick JE. 1994. A cell initiating human acute myeloid leukaemia after transplantation into SCID mice. Nature 367:645-648.

Lessard J, Sauvageau G. 2003. Bmi-1 determines the proliferative capacity of normal and leukaemic stem cells. Nature 423:255-260.

Leung C, Lingbeek M, Shakhova O, Liu J, Tanger E, Saremaslani P, Van Lohuizen M, Marino S. 2004. Bmi1 is essential for cerebellar development and is overexpressed in human medulloblastomas. Nature 428:337-341.

Li C, Heidt DG, Dalerba P, Burant CF, Zhang L, Adsay V, Wicha M, Clarke MF, Simeone DM. 2007. Identification of pancreatic cancer stem cells. Cancer Res 67:1030-1037.

Li X, Lewis MT, Huang J, Gutierrez C, Osborne CK, Wu MF, Hilsenbeck SG, Pavlick A, Zhang X, Chamness GC, Wong H, Rosen J, Chang JC. 2008. 
Intrinsic resistance of tumorigenic breast cancer cells to chemotherapy. J Natl Cancer Inst 100:672-679.

Molofsky AV, Pardal R, Iwashita T, Park IK, Clarke MF, Morrison SJ. 2003. Bmi-1 dependence distinguishes neural stem cell self-renewal from progenitor proliferation. Nature 425:962-967.

Morrison SJ, Spradling AC. 2008. Stem cells and niches: Mechanisms that promote stem cell maintenance throughout life. Cell 132:598-611.

0'Brien CA, Pollett A, Gallinger S, Dick JE. 2007. A human colon cancer cell capable of initiating tumor growth in immunodeficient mice. Nature 445: 106-110.

Park IK, Qian D, Kiel M, Becker MW, Pihalja M, Weissman IL, Morrison SJ, Clarke MF. 2003. Bmi-1 is required for maintenance of adult self-renewing haematopoietic stem cells. Nature 423:302-305.

Phillips TM, McBride WH, Pajonk F. 2006. The response of CD24(-/low)/ CD44+ breast cancer-initiating cells to radiation. J Natl Cancer Inst 98: 1777-1785.

Prince ME, Sivanandan R, Kaczorowski A, Wolf GT, Kaplan MJ, Dalerba P, Weissman IL, Clarke MF, Ailles LE. 2007. Identification of a subpopulation of cells with cancer stem cell properties in head and neck squamous cell carcinoma. Proc Natl Acad Sci USA 104:973-978.

Reya T, Clevers H. 2005. Wnt signalling in stem cells and cancer. Nature 434:843-850.

Reya T, Morrison SJ, Clarke MF, Weissman IL. 2001. Stem cells, cancer, and cancer stem cells. Nature 414:105-111.

Ricci-Vitiani L, Lombardi DG, Pilozzi E, Biffoni M, Todaro M, Peschle C, De Maria R. 2007. Identification and expansion of human colon-cancerinitiating cells. Nature 445:111-115.
Schuettengruber B, Chourrout D, Vervoort M, Leblanc B, Cavalli G. 2007. Genome regulation by polycomb and trithorax proteins. Cell 128:735-745.

Shah AN, Summy JM, Zhang J, Park SI, Parikh NU, Gallick GE. 2007. Development and characterization of gemcitabine-resistant pancreatic tumor cells. Ann Surg Oncol 14:3629-3637.

Singh SK, Clarke ID, Terasaki M, Bonn VE, Hawkins C, Squire J, Dirks PB. 2003. Identification of a cancer stem cell in human brain tumors. Cancer Res 63:5821-5828.

Surveillance Epidemiology and End Results (SEER) database. National Cancer Institute, http://seer.cancer.gov/index.html, last accessed December 29, 2008.

Thayer SP, di Magliano MP, Heiser PW, Nielsen CM, Roberts DJ, Lauwers GY, Qi YP, Gysin S, Fernandez-del Castillo C, Yajnik V, Antoniu B, McMahon M, Warshaw AL, Hebrok M. 2003. Hedgehog is an early and late mediator of pancreatic cancer tumorigenesis. Nature 425:851-856.

Todaro M, Alea MP, Di Stefano AB, Cammareri P, Vermeulen L, Iovino F, Tripodo C, Russo A, Gulotta G, Medema JP, Stassi G. 2007. Colon cancer stem cells dictate tumor growth and resist cell death by production of interleukin4. Cell Stem Cell 1:389-402.

van de Wetering M, Sancho E, Verweij C, de Lau W, Oving I, Hurlstone A, van der Horn K, Batlle E, Coudreuse D, Haramis AP, Tjon-Pon-Fong M, Moerer P, van den Born M, Soete G, Pals S, Eilers M, Medema R, Clevers H. 2002. The beta-catenin/TCF-4 complex imposes a crypt progenitor phenotype on colorectal cancer cells. Cell 111:241-250.

Woodward WA, Chen MS, Behbod F, Alfaro MP, Buchholz TA, Rosen JM. 2007. WNT/beta-catenin mediates radiation resistance of mouse mammary progenitor cells. Proc Natl Acad Sci USA 104:618-623. 